\title{
Impact of Building and Refrigeration System's Parameters on Energy Consumption in the Potato Cold Storage
}

\author{
Ramkishore Singh $^{1}$, S P Singh ${ }^{2} \&$ I J Lazarus ${ }^{1}$ \\ ${ }^{1}$ Department of Physics, Durban University of Technology, Durban 4000, South Africa \\ ${ }^{2}$ School of Energy \& Environmental Studies, Takashashila Campus, Khandwa Road, Devi Ahilya University, \\ Indore- 452017, India \\ Correspondence: Ramkishore Singh, Department of Physics, Durban University of Technology, Durban 4000, \\ South Africa. Tel: 27-31-3735359; Fax: 27-31-373-5264. E-mail: singh.ramkishore@gmail.com
}

Received: September 22, 2014 Accepted: October 1, 2014 Online Published: November 23, 2014

doi:10.5539/eer.v4n3p126 URL: http://dx.doi.org/10.5539/eer.v4n3p126

\begin{abstract}
Cold storage is a key element for long term preservation and distribution of perishable items. A large quantity of perishable items is gone wastage every year due to inadequate storage facility in the countries like India. Their energy extensive refrigeration process makes them accountable for substantial share of total energy consumption in the country. Moreover, energy inefficiency in operation and building designs in the existing cold storages inhibits expansion of desirable storage facility. This study aims to explore the building and refrigeration system's parameters that may influence the overall energy consumption in the storage. A survey was conducted in ten Indian potato cold storages and detail data of their energy consumption, building construction and refrigeration systems was collected. The collected data was analyzed quantitatively and qualitatively. Trend analysis technique was also used to establish relationship between specific energy consumption and identified parameters. Results show that the utilization factor has major impact on the energy consumption in the storages and the existing cold storages are not utilizing their storage capacities fully. Comparatively higher energy consumption was observed in the cold storages that have low utilization factors. Building aspect ratios and effective U-value of the building envelop were also identified one of the crucial parameters that can play a major role to improve the energy performance of the cold storages. As expected, a negligible variation in the specific energy consumption of the storages with the specific installed refrigeration systems and AHUs was observed.
\end{abstract}

Keywords: potato cold storage, energy efficient building, refrigeration, capacity utilization factor, effective U-value

\section{Introduction}

Energy crises, global warming and food security are major concerns for the whole world and need to be given immediate attention. Cold storages are essential for food security as well as for quality of perishable items, however, operation of the storages is an energy extensive process and consumes substantial amount of the total energy consumption in the countries like India. As of 2012, India had approximately 6,300 cold storages, with a total storage capacity of 30.11 million metric tons. Recently, it was estimated that the cold storage capacity in India needs to doubled, to a total of 61.13 million metric tons, to accommodate the yearly production of the perishable food items in the country (Sridar, 2013). Despite that more than $80 \%$ of the existing storage facility is being used for potato, fruits and vegitables storage only(Singh, Singh, \& Lazarus, 2014), a sizable quantity (approximately 10-15\%) of the total potato production is gone wastage every year due to lack of sufficient storage facility in the country (Agriwatch, 2012). Also, the Indian cold storages are mainly run on the grid electricity and their energy expenses account approximately $28 \%$ of the total costs(TERI, 2012). Therefore, the energy performance of the existing cold storage facility needs to be assessed and discussed properly because the poor performance of the storage facilities not only increase the energy consumption but also responsible for low quality of refrigerated product (Gottschalk, K., Nagy, L., 2003; Nourian, F., Ramaswamy, H.S., 2003). In recent past, few researchers have emphasized to improve the energy efficiency and operation in the potato storages in different parts of the world including India (Chourasia \& Goswami, 2009; Hasse, H., Becker, M., Grossmann, K., Maurer, 1996; Marchant, A.N. and Davies, 1994; Marchant, A.N., Lidstone, P.H. and Davies, 1994; USAID, 2009; Xie, J., Qu, X.H., Shi ,J.Y. and Sun, 2006). Chourasia and Goswami (Chourasia \& Goswami, 2009) 
discussed few important factors that can influence the energy consumption in the potato cold storage. They also suggested some possible solutions to improve the energy performance of the storage. Hasse et al. (Hasse, H., Becker, M., Grossmann, K., Maurer, 1996) accessed the potential for energy savings by improving automation and control in the refrigeration system. Devres and Bishop (Devres, Y. O. and Bishop, 1995) studied the energy consumption, using a theoretical model, in a real potato cold storage in the UK climate. Xie et al. (Xie, J., Qu, X. H., Shi, J. Y. and Sun, 2006) analysed several design parameters such as corner baffle, the stack mode of foodstuffs for a minitype cold storage and analysed the parameters that affect the flow field in the storage. Marchant and coworkers (Marchant, A.N. and Davies, 1994; Marchant, A.N., Lidstone, P.H. and Davies, 1994) designed a part of an expert system controller by using artificial intelligent techniques to improve the indoor environment as well as the energy performance of the cold storage. Moreover, few researchers also suggested the refrigeration units, which can run on solar energy (Grenier, Ph., Guilleminot, J.J., Meunier and Pons, 1988; Oertel, K. and Fischer, 1998) and biomass energy (Anbazhaghan, Saravanan, \& Renganarayanan, 2005).

Despite numerous efforts that were made in this area, effect of building and refrigeration system's parameters on the energy consumption in the potato storage has hardly been explored. This study aims to identify and figure out the parameters those can influence energy consumption in existing potato cold storages and can be helpful in further development of new energy efficient cold storages. In this study, particularly, the impact of aspect ratio and effective overall heat transfer coefficient on the energy consumption in the potato cold storages were discussed using the trend analysis. Also, the variation in energy consumption with capacity utilization factor was analyzed. Results of this study could be important reference materials for the cold storage designers, architects, consultants and owners for assessing the energy consumption patterns in the existing storages and selecting a more accurate approach for future development of the energy efficient storages. However, study is limited for a small cluster in the composite climate and possibly results may vary in other parts of the same climate or in other climatic zones. Therefore, similar studies in other climatic zones are suggested, which could lead to more generalized results.

\section{Methodology}

\subsection{Study Region}

A survey, for energy consumption, building and refrigeration systems' parameters, was conducted in a few potato cold storages in and around Indore City. The city is located in the mid-western part of India, South of the Tropic of Cancer $\left(22.71^{\circ} \mathrm{N}, 75.91^{\circ} \mathrm{E}\right)$, and has been selected one of the special economic zones (SEZs) in India ("Indore Special Economic Zone," 2003). The city has maximum number of cold storages (approximately 52) in the region (Singh et al., 2014), which play a vital role in regulating the demand of perishable products in the region. More than $50 \%$ of the existing storage facility is being used for potato storage only (Singh et al., 2014). The climate of the Indore is described as composite climate having three distinct seasons summer, monsoon and winter.

\subsection{Data Collection and Analysis}

Present study intends to determine the energy consumption pattern in the potato cold storages through field survey and experimental procedures. The energy consumption and other detail were collected from a few cold storages in the selected region using sample survey technique. A detailed questionnaire was prepared and supplied randomly to the potato cold storages. The surveyed cold storages were a mix of private and cooperative categories. Responsible people e.g. owners, managers and operators at each of the cold storages were asked to answer all the questions stated in the questionnaire. The information was asked in the questionnaire specifically to obtain data about their electrical energy consumptions, storage patterns, construction pattern, design features, aspect ratios and orientation of the storage building as well as types of refrigeration system, frequency of use and their capacities which were being used. Also, the surveyed cold storages were visited physically a number of times for validating the information obtained through the questionnaire and to enable the respondents answer correctly to the questions in the questionnaire. Moreover, a few selected persons for example owner, manager and operator were interviewed and information, on technical, economic and social challenges in running the storages, were collected. In this article, only relevant information is presented. The monthly electricity bills were also collected directly from the responsible energy supplying agency in the region to justify and maintain the accuracy and completeness of the energy consumption data of the surveyed cold storages, All of the received questionnaires were examined carefully and only ten questionnaires, which had most of the desirable information and covered complete range of storage capacities, were analyzed quantitatively. The storage capacities of the selected cold storages vary between 6000 tons and 15000 tons (Singh, R., Singh, S.P., 2010). 


\subsubsection{Energy Consumption and Storage Patterns}

The energy consumption and stored potato data were collected for the selected cold storages for four consecutive years. Yearly storage pattern of potato in the storages and their respective specific energy consumptions (SEC) are presented in Figure 1 and Table 1 respectively.

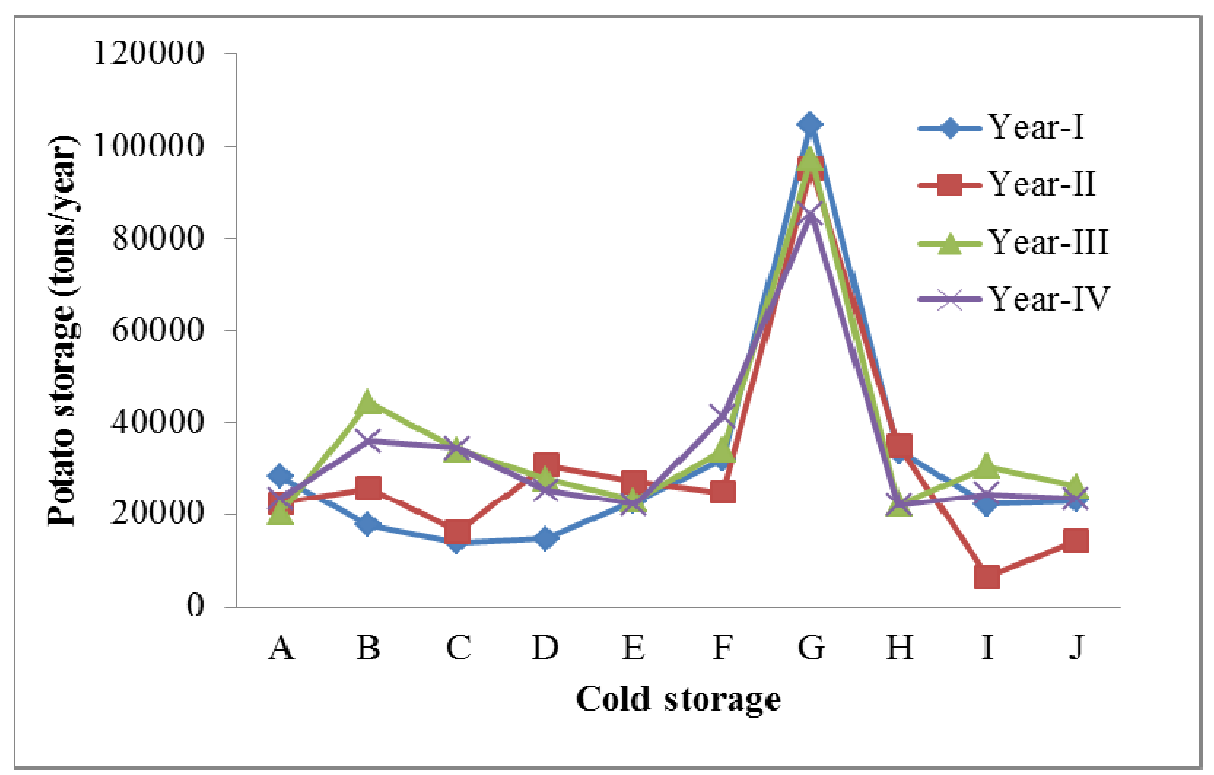

Figure 1. Annual potato storage patterns for years I to IV

Table 1. Annual Specific Energy Consumption (SEC) of Potato cold storages

\begin{tabular}{llllll}
\hline \multirow{2}{*}{$\begin{array}{l}\text { Cold } \\
\text { Storage }\end{array}$} & \multicolumn{5}{c}{ Annual specific energy consumption(kWh/ton) } \\
\cline { 2 - 5 } & Year-IV & Year-III & Year-II & Year-I & Average \\
\hline A & 10.07 & 10.86 & 10.77 & 10.49 & 10.5 \\
B & 10.01 & 9.92 & 12.33 & 13.69 & 11.5 \\
C & 9.00 & 9.90 & 12.79 & 13.00 & 11.2 \\
D & 14.63 & 14.96 & 13.67 & 21.47 & 16.2 \\
E & 12.79 & 13.38 & 11.30 & 12.58 & 12.5 \\
F & 9.47 & 9.92 & 10.17 & 9.66 & 9.8 \\
G & 9.70 & 10.84 & 10.38 & 10.61 & 10.4 \\
H & 15.56 & 16.82 & 9.64 & 10.80 & 13.2 \\
I & 11.35 & 12.05 & 26.08 & 13.81 & 15.8 \\
J & 12.15 & 8.90 & 11.93 & 12.38 & 11.3 \\
\hline
\end{tabular}

\subsubsection{Building Construction Pattern}

The buildings were found to be constructed with a slanted type roof made of a corrugated sheet of tin or asbestos cement sheets. The buildings also have a false flat ceiling under the slanted roof, which keeps outdoor and indoor environment separate. Section between the slanted roof and the false ceiling also has a few windows, which allow continuous exchange of the air in the section with the ambient air. This air exchange helps to remove the heat effect created by the solar radiation falling directly on the slanted roof section. The air gap between the slanted part and the flat ceiling also created an extra insulation, which reduces the heat transfer between storage chamber and the outdoor ambient environment. In all of the cold storages, similar construction pattern was observed. The construction materials used in the construction of the storage buildings are mainly bricks, thermocole insulation, wooden rafter, wood powder, plaster and asphalt sheet. The buildings also have a 
few columns and beams made of RCC, however, effect of column and beams were not taken into consideration in this study. It can be observed from the data that the construction materials used in the construction of the cold storages' buildings are same, however, thicknesses of some construction materials vary. The thickness and arrangements of construction materials observed in the construction of walls and roof in the selected storage buildings are given in Tables 2 and 3.

Table 2. Variation in thickness of the construction materials used in walls in different cold storage

\begin{tabular}{lllllll}
\hline \multirow{2}{*}{ Cold Storage } & \multicolumn{7}{c}{ Thickness $(\mathrm{m})$} \\
\cline { 2 - 6 } & Plaster & Brick & Plaster & Thermocole & Iron net & Plaster \\
\hline A & 0.0254 & 0.3560 & 0.0254 & 0.0762 & 0.003 & 0.0380 \\
B & 0.0254 & 0.2286 & 0.0254 & 0.0762 & 0.003 & 0.0380 \\
C & 0.0254 & 0.2286 & 0.0254 & 0.1016 & 0.003 & 0.0380 \\
D & 0.0254 & 0.2286 & 0.0254 & 0.0762 & 0.003 & 0.0127 \\
E & 0.0381 & 0.2286 & 0.0254 & 0.1016 & 0.003 & 0.0380 \\
F & 0.0381 & 0.2286 & 0.0127 & 0.0809 & 0.003 & 0.0380 \\
G & 0.0254 & 0.2286 & 0.0127 & 0.0800 & 0.003 & 0.0254 \\
H & 0.0254 & 0.2286 & 0.0191 & 0.0635 & 0.003 & 0.0127 \\
I & 0.0254 & 0.2286 & 0.0254 & 0.0762 & 0.003 & 0.0127 \\
J & 0.0254 & 0.2286 & 0.0254 & 0.0800 & 0.003 & 0.0188 \\
\hline
\end{tabular}

Note: Actual measurement was taken in inches.

Table 3. Variation in thickness of construction materials used in ceiling in different cold storage

\begin{tabular}{lllllll}
\hline \multirow{2}{*}{$\begin{array}{l}\text { Cold } \\
\text { Storage }\end{array}$} & Thickness $(\mathrm{m})$ & & & & \\
\cline { 2 - 6 } & Wood Powder & Asphalt sheet & Thermocole & Iron & Plaster & Wood \\
\hline A & 0.2032 & -- & 0.1016 & 0.003 & 0.038 & 0.0380 \\
B & 0.0508 & 0.004 & 0.1016 & 0.003 & 0.038 & 0.0635 \\
C & 0.1524 & 0.004 & 0.1016 & -- & -- & 0.0254 \\
D & 0.0762 & 0.004 & 0.0762 & -- & -- & 0.0254 \\
E & 0.0508 & 0.012 & 0.0762 & -- & -- & 0.1016 \\
F & 0.0381 & 0.004 & 0.1016 & -- & -- & 0.0254 \\
G & -- & 0.004 & 0.1300 & -- & -- & 0.0254 \\
H & 0.0508 & 0.004 & 0.0762 & -- & -- & 0.0254 \\
I & 0.0508 & 0.004 & 0.0762 & -- & -- & 0.0254 \\
J & 0.1524 & -- & 0.0254 & -- & -- & 0.0762 \\
Note: Actual measurement was taken in inches. & & & & \\
\hline
\end{tabular}

A representative arrangement for the wall and the flat ceiling constructions is shown in Figure 2. Thickness of each layer in actual construction varies from one building to other (See Tables $2 \& 3$ ). 


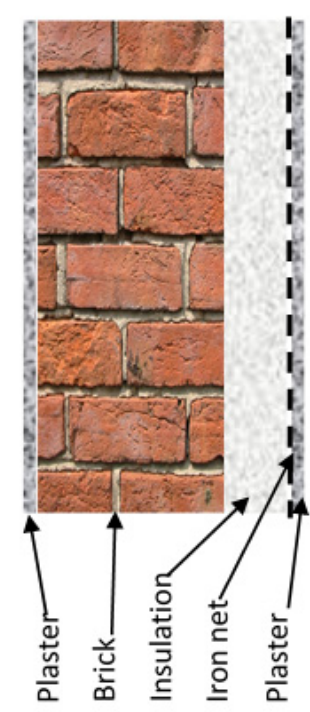

a) wall construction pattern

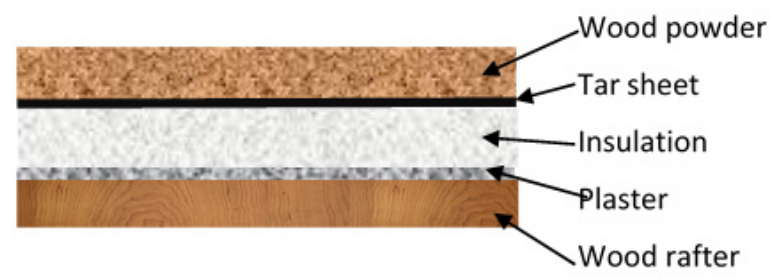

b) ceiling construction pattern

Figure 2. Construction patterns of wall and roof

\subsubsection{Calculation of Ueff}

In this study, $U_{\text {eff }}$ represents effective overall heat transfer coefficient for complete building envelop and is estimated by following equation:

$$
U_{\text {eff }}=\left(U_{r} \times A_{r}+U_{w} \times A_{w}\right) /\left(A_{r}+A_{w}\right)
$$

Where $U_{r}, U_{w}, A_{r}, A_{w}$ represent overall heat transfer coefficients and area of roof and walls respectively.

The overall heat transfer coefficient is calculated using the following general formula:

$$
1 / U=R=1 / h_{i}+l_{1} / k_{1}+l_{2} / k_{2} \ldots \ldots . l_{n} / k_{n}+1 / h_{o}
$$

Where $h_{i}, h_{o}$ are heat transfer coefficients for inner and outer layer of air films, $l_{1}, l_{2} \ldots . . l_{n}$ and $k_{1}, k_{2}, \ldots . k_{n}$ are thicknesses and thermal conductivities for the construction materials used in layer 1 , layer $2 \ldots$. layer $n$ respectively.

The effects of convection and radiation on the inner and outer surfaces of building components (e.g. walls and roof) are usually included in the combined heat transfer coefficients $h_{i}$ and $h_{o}$, respectively. The conductivities of each the construction materials used in the calculation is listed in Table 4. The thicknesses of the construction layers used in the calculation of overall U-factor of the buildings' components and eventually $U_{\text {eff }}$ of the building envelops were taken from the Tables 2 and 3. Surface area of each surface was calculated using the building dimensions given in Table 5. The $U_{\text {eff }}$ has been correlated with the energy consumption later in the results and discussion section.

Table 4. Thermal conductivity of construction materials

\begin{tabular}{llllllll}
\hline & & & & & \multicolumn{2}{c}{ Wood rafter/ } & \\
\cline { 5 - 6 } & Plaster & Brick & Thermocole & Iron Net & Wood powder & Asphalt \\
\hline Thermal conductivity $(\mathrm{W} / \mathrm{m}-\mathrm{K})$ & 0.72 & 0.84 & 0.035 & 53.6 & $0.13 / 0.1$ & 0.5 & \\
\hline
\end{tabular}


Table 5. Dimensions of the cold storages

\begin{tabular}{|c|c|c|c|c|}
\hline \multirow[t]{2}{*}{ Cold storage } & \multirow[t]{2}{*}{ Chamber } & \multicolumn{3}{|c|}{ Dimensions in $(\mathrm{m})$} \\
\hline & & Length & Width & Height \\
\hline \multirow[t]{2}{*}{$\bar{A}$} & 1 & 58.87 & 25.91 & 5.94 \\
\hline & 2 & 24.38 & 25.91 & 18.29 \\
\hline \multirow[t]{2}{*}{ B } & 1 & 47.52 & 29.7 & 20.46 \\
\hline & 2 & 39.62 & 30.48 & 18.29 \\
\hline $\mathrm{C}$ & & 31.32 & 31.32 & 20.1 \\
\hline D & & 75.41 & 30.48 & 15.24 \\
\hline $\mathrm{E}$ & & 33.53 & 30.48 & 19.81 \\
\hline \multirow[t]{2}{*}{$\mathrm{F}$} & 1 & 33.53 & 22.86 & 9.14 \\
\hline & 2 & 30.48 & 30.48 & 12.8 \\
\hline \multirow[t]{4}{*}{ G } & 1 & 68.53 & 12.19 & 5.94 \\
\hline & 2 & 44.73 & 19.05 & 10.67 \\
\hline & 3 & 25.44 & 15.21 & 11.25 \\
\hline & 4 & 58.82 & 38.41 & 14.63 \\
\hline $\mathrm{H}$ & & 83.12 & 30.48 & 17.76 \\
\hline I & & 45.72 & 36.58 & 15.24 \\
\hline $\mathrm{J}$ & & 45.72 & 36.58 & 15.24 \\
\hline
\end{tabular}

\subsubsection{Refrigeration System}

During the survey, it was observed that in all cold storages, a conventional vapour compression refrigeration (VCR) system is being used to produce desirable indoor storage environmental conditions. The temperature and humidity in all the surveyed storages were found to be maintained at $4^{\circ} \mathrm{C}$ and between 80 and $95 \%$ respectively. Compressors, condensers and air handling units are main components of refrigeration unit. It was noted that reciprocating heavy duty compressors are being used in all the selected storages. The pictorial view of the compressor room in the refrigeration system used in one of the surveyed cold storages is shown in Figure 3.

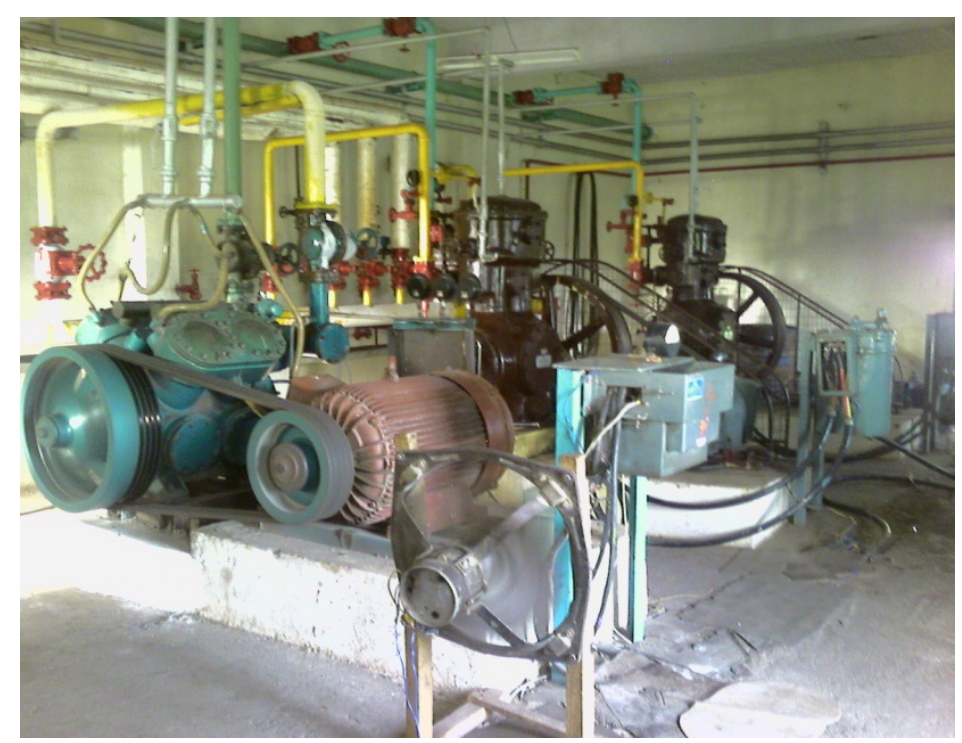

Figure 3. Compressor's room of a refrigeration unit in a cold storage

Two types of air handling units, i) bunker type and ii) fan coil units (FCUs) are being used for air circulation and maintain the temperature in the refrigerated chambers(Figure 4). About 80 percent of the cold storages were found to be using bunker type air handling units and other $20 \%$ are using fan coil unit. The air handling units were found to be installed in the upper most section of the cold storages chambers and are being used to re-circulate the indoor air continuously. It was also informed by responsible persons that the highly $\mathrm{CO}_{2}$ concentrated indoor air of the storage chambers is completely replaced with fresh outdoor air once every day. The process of air replacement is generally taken place in the early morning hours( between 2 am and $4 \mathrm{am}$ ) or 
when ambient air is at minimum temperature level of the day, so that the risk of high cooling load due to higher ambient temperature could be avoided.

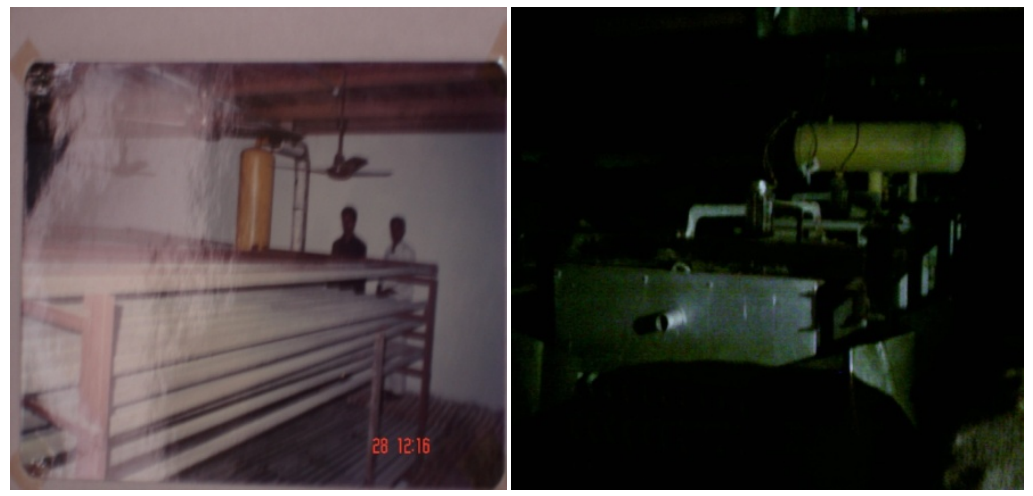

Figure 4. Air handling unit a) Banker type b) Fan coil unit

\section{Results and Discussions}

The energy consumption pattern of the cold storages is represented by the specific energy consumption, which is could be a suitable parameter to compare the energy performance of the storages. The table 1 show that the yearly specific energy consumption varies between 9.00 and $15.56 \mathrm{kWh} / \mathrm{ton}, 8.90$ and $16.82 \mathrm{kWh} /$ ton, 9.64 and $26.08 \mathrm{kWh} /$ ton and 9.66 and $21.47 \mathrm{kWh} /$ ton for years IV, III, II and I respectively. An average specific energy consumption varies between 9.8 and $16.2 \mathrm{kWh} /$ ton/year. This large variation could be due to variation in operation pattern and difference in refrigeration system's performance. The variation also indicates the possibilities of a significant energy savings in some of the storages by implementing appropriate energy saving measures. Some of the possible measures to improve the energy efficiency in the cold storages were discussed in our previous study (Singh, R., Singh, S.P., 2010). The variation in specific energy consumption could also be influenced by the building and refrigeration systems' parameters (e.g. capacity utilization factor (CUF), overall heat transfer coefficient $\left(\mathrm{U}_{\text {eff }}\right)$, aspect ratios of buildings, capacities of refrigeration units and air handling units). To assess the possible relationship between these parameters and the energy consumptions, trend analysis were used. The trend analysis is particularly helpful for identifying the general behavior of the interpreter and also examines changes in its behavior across the whole spectrum of its numerical values.

\subsection{Effect of Capacity Utilization}

During the survey, it was observed that only a small fraction of total storage capacities of the cold storages were utilizing. The capacity utilization may depend on the crop yield in the respective year and demand of the produce in the market. If crop yield is high, a higher storage capacity will require to accommodate the maximum produce, while higher market demand may lead to lower storage requirement. The cold storage capacity utilization factor is determined as follows:

$$
\text { Capacity utilization factor }=\frac{\text { Used capacity of cold storage(tons) }}{\text { Full capacity of cold storage(tons) }}
$$

Figure 5. shows the relationship between the average specific energy consumption as a function of capacity utilization factor. 


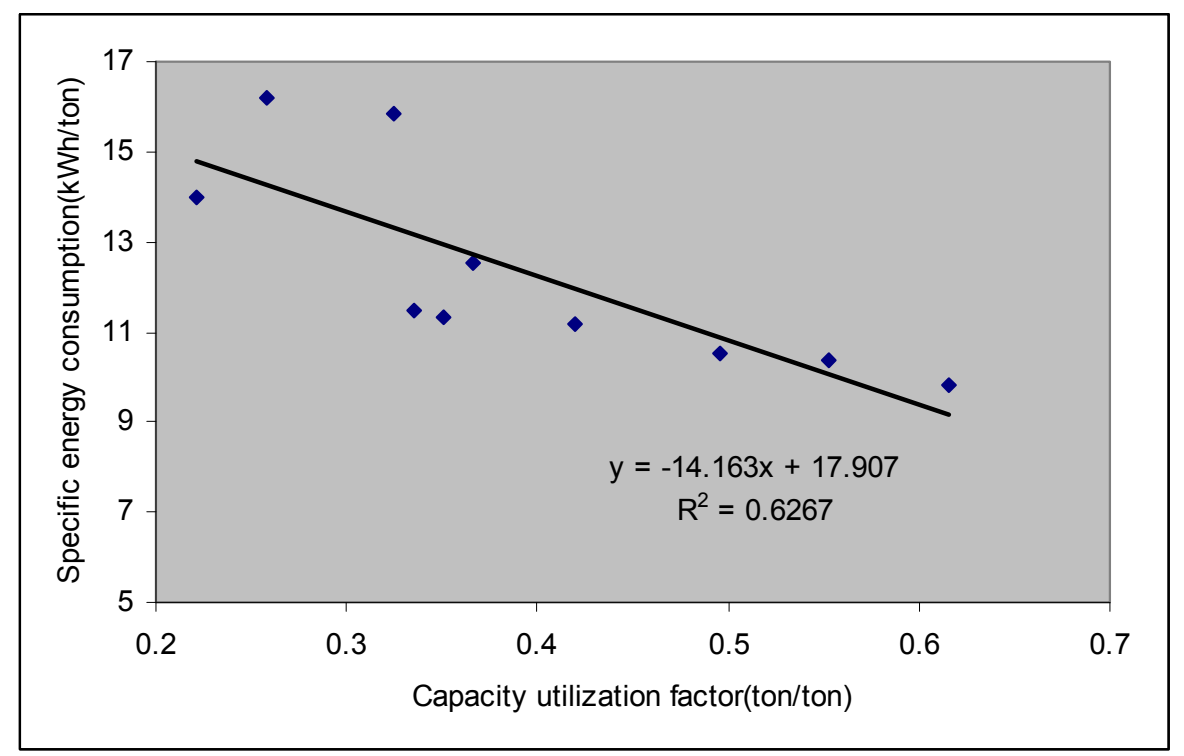

Figure 5. SEC vs. capacity utilization

It can clearly be observed from Fig.5 that the capacity utilization factor influences the specific energy consumption significantly. An average negative slope of the SEC with changes in CUF was estimated $14.163 \mathrm{kWh} /$ ton that means the increase in CUF by 0.1 decreases the energy consumption by $1.46 \mathrm{kWh} / \mathrm{ton}$. The negative slope of the trend line indicates higher energy performance for higher utilization of the storage, which is obvious. It would also be worth to mention here that none of the storage showed the capacity utilization factor 1 . The low range of CUF varies between 0.2 and 0.6 is an indication of poor utilization of the storage facility and huge potential of maximizing energy efficiency of the potato storages. If the storages utilize their storage capacities at maximum strength, the current minimum energy consumption rate, $9 \mathrm{kWh} / \mathrm{ton} / \mathrm{year}$, could be reduced further by a significant factor. Therefore, it is recommended that the maximum utilization of the storage capacities should be ensured. The maximum utilization can be done by dividing the larger storage chambers into many smaller storage chambers connecting with a separate smaller refrigeration unit. A separate assessment is required to optimize the size of the storage chamber, which is not part of this study and can be done separately.

\subsection{Effect of Aspect Ratio of Building}

Shape of the building envelop, determined by aspect ratios, plays a crucial role in the energy performance of the storage because most part of the external surface area of the building expose directly to sun (Singh, S.P., Singh, R.K., Sodha, 2009). Compactness is expressed by the aspect ratios of building envelop for a specified volume. As heat losses are proportional to the building surface area, therefore, higher compactness results in lower heat transfer and improves the energy efficiency. Figure 6 shows the effect of aspect ratios of building envelop on the average specific energy consumption. In this figure, data from only single chamber cold storages (C,D,E,H,I and $\mathrm{J}$ ) is presented due to unavailability of separate energy data for each buildings attached with the same refrigeration system. For example, cold storage A has two buildings with different dimensions and orientation and operated using a combined refrigeration system consists a few compressors, a condenser and separate air handling units. 


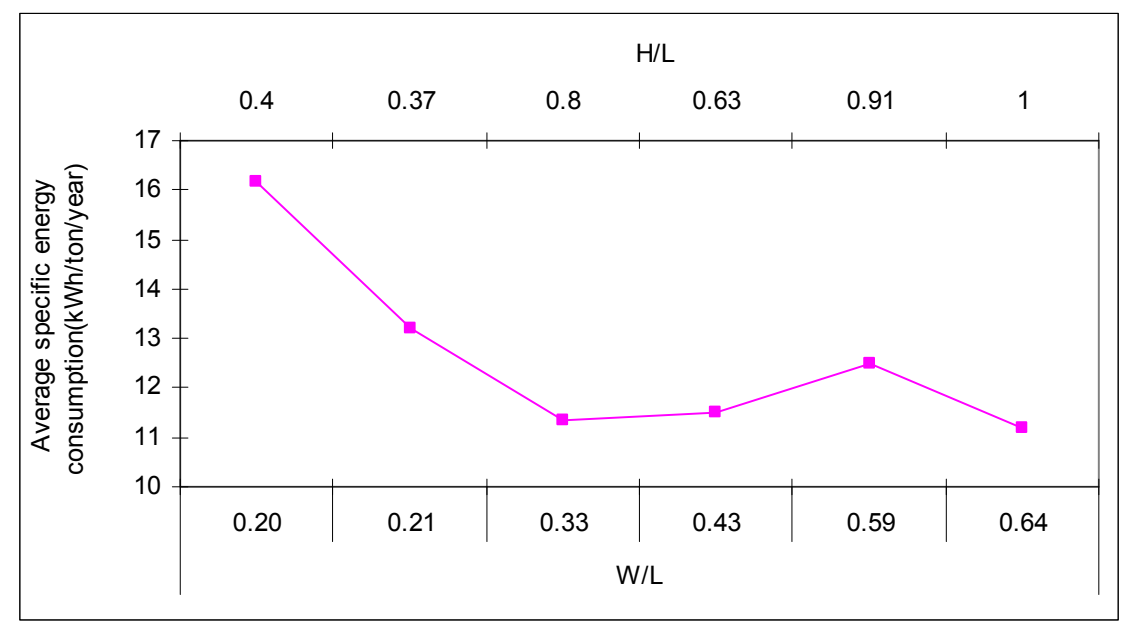

Figure 6. SEC vs. aspect ratios

It can be observed from the fig. 6 that the average specific energy consumption varies with the aspect ratios of the cold storages. The building of the aspect ratios $\mathrm{W} / \mathrm{L}=0.64, \mathrm{H} / \mathrm{L}=1$ was found to be the most energy efficient one. The buildings of the aspect ratios of $\mathrm{W} / \mathrm{L}=0.33, \mathrm{H} / \mathrm{L}=0.8$ and $\mathrm{W} / \mathrm{L}=0.43, \mathrm{H} / \mathrm{L}=0.63$ demand a higher energy compare to the best one but the difference is not significant. Best option in terms of energy efficiency might change with location and climatic condition and, therefore, similar studies for other locations in same climatic zone and/or other climatic zones are suggested for generalizing the results. Moreover, a separate analysis is required for the cold storages having multiple buildings served by the one refrigeration system.

\subsection{Effect of U Value}

As discussed previously in section 2.2.3, the overall heat transfer coefficient of building envelop is another important parameter that affects the thermal performance of the building critically. The U-value entirely depends on the materials used in the construction and their thicknesses. Figure 7 shows a liner relationship between the overall effective heat transfer coefficient and the specific energy consumption of the cold storages. Though the relationship is not very strong but a higher specific energy demand can be observed for higher effective heat transfer coefficient as expected. A separate study for an optimization of effective overall heat transfer coefficient values, for minimum energy demand, is required for the storage buildings in different climates including composite climate.

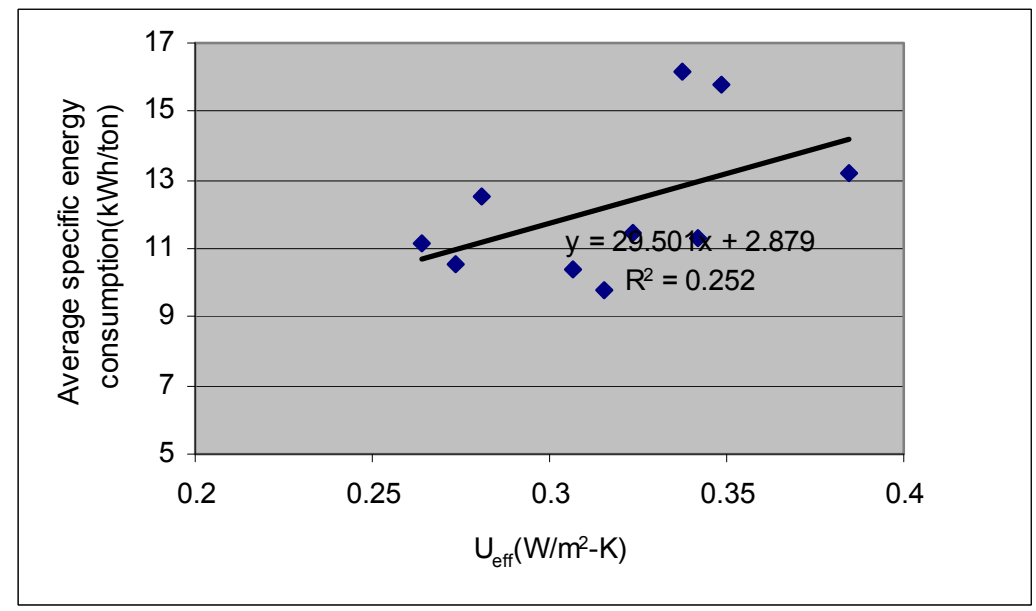

Figure 7. SEC vs Ueff 


\subsection{Effect of Size of Refrigeration and Air Handling Units}

In this section, an effect of refrigeration and air handling units on the energy consumption in the cold storages was also discussed. Figures $8 \& 9$ show the variation in specific energy consumption with installed specific refrigeration and AHU capacities. It should be worth to mention that, the installed specific capacities were calculated based on the designed storage capacities of the storages and not for the stored produced at the time of survey.

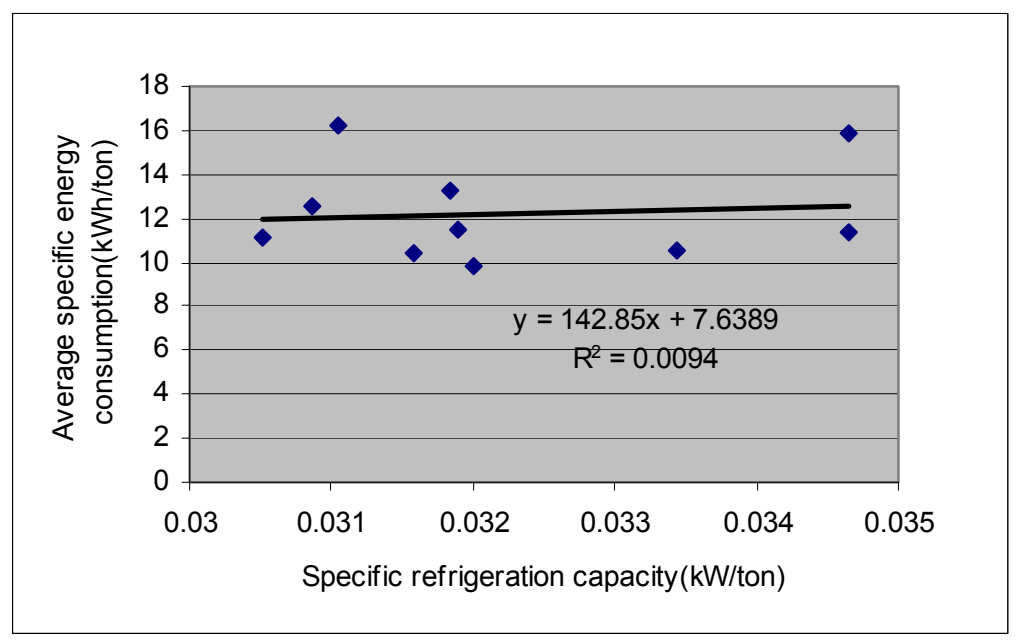

Figure 8 . SEC vs. Specific refrigeration capacity

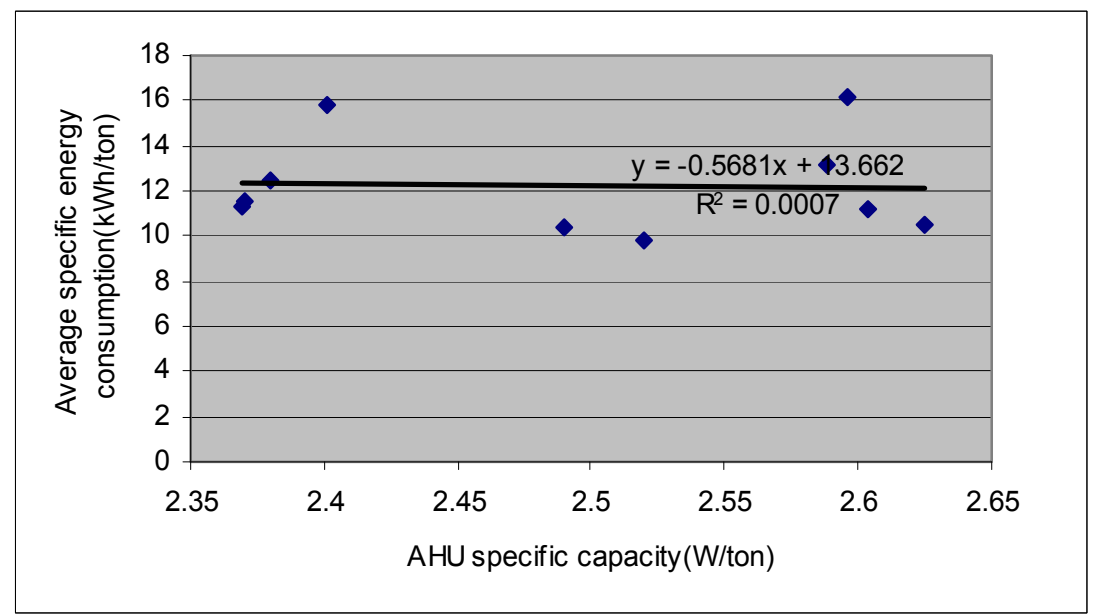

Figure 9. SEC vs. Specific AHU capacity

The results presented in Fig. 8 show an unnoticeable increase in the average specific energy consumption the with specific installed refrigeration capacity. Moreover, $\mathrm{R}^{2}$ value show that there is not a considerable relationship between two parameter which was expected. The variation in the average specific energy consumption could be due to varying solar thermal loads of buildings having different aspect ratios for equal storage capacities. Fig. 9 shows a negative relationship, however, again low $\mathrm{R}^{2}$ value indicate the independency of the average specific energy consumption on the installed AHU capacities. The variation in the energy demand could be due to similar reasons explained for installed refrigeration capacities. A further similar analysis can be done with large number of sample size in other climates and locations to develop common and more effective design guidelines for developing new and energy efficient cold storages.

\section{Conclusion}

A survey was conducted, in ten potato cold storages, for their energy consumptions, storage patterns, construction patterns of buildings and the installed refrigeration systems. Based on the collected that impact of various building parameters i.e. aspect ratios and $\mathrm{U}_{\text {eff }}$, and utilization capacity was analyzed and discussed. It was observed that the specific energy consumption varies between $9 \mathrm{kWh} /$ ton/year and $26 \mathrm{kWh} /$ ton/year among 
the surveyed cold storages. This huge variation indicate a substantial potential to improve the energy efficiency in the cold storages. Moreover, a poor utilization factor observed between 0.2 and 0.6 , which indicates partial utilization of the available storage capacity. The energy consumption in the cold storages with low utilization factor was observed higher which means operating the storage in partially filled condition is not a good practice from energy efficiency point of view. The capacity utilization factor could be increased by creating a number of smaller storage chambers, instead of one bigger chamber, connected with a separate refrigeration unit. The aspect ratios of building envelops and effective U- value also influence the energy consumption significantly. Therefore, dimensions of the storage buildings, construction materials and their thicknesses should be decided wisely beforehand the final construction. Results also reveal that the specific energy consumption found almost invariant with the installed specific refrigeration and AHU capacities as expected.

\section{References}

Agriwatch. (2012). Market intelligence system: Baseline data for potato and onion. Retrieved from http://sfacindia.com/PDFs/Onion \& Potato Baseline Report.pdf

Anbazhaghan, N., Saravanan, R., \& Renganarayanan, S. (2005). Biomass Based Sorption Cooling Systems for Cold Storage Applications. International Journal of Green Energy, 2(4), 325-335. http://dx.doi.org/10.1080/01971520500287891

Chourasia, M. K., \& Goswami, T. K. (2009). Efficient design , operation, maintenance and management of cold storage compressor, 1(1), 70-93.

Devres, Y. O., \& Bishop, C. F. H. (1995). Computer model for weight loss and energy conservation in a fresh produce Refrigerated Store. Applied Energy, 50, 97-117. http://dx.doi.org/10.1016/0306-2619(95)92627-6

Gottschalk, K., Nagy, L., \& F. I. (2003). Improved climate control for potato stores by fuzzy controllers. $\begin{array}{llll}\text { Computers and Electronics in } & \text { Agriculture, }\end{array}$ http://dx.doi.org/10.1016/S0168-1699(03)00016-4

Grenier, Ph., Guilleminot, J. J., Meunier, \& Pons, F. M. (1988). Solar powered solid absorption cold store. Journal of Solar Energy Trans. ASME, 1b(3), 192-197. http://dx.doi.org/10.1115/1.3268256

Hasse, H., Becker, M., Grossmann, K., \& Maurer, G. (1996). Top-down model for dynamic simulation of cold-storage plants. International Journal of Refrigeration, 19(1), 10-18. http://dx.doi.org/10.1016/0140-7007(95)00077-1

Indore Special Economic Zone. (2003). http://www.indoresez.gov.in/. Retrieved January 22, 2013, from http://www.indoresez.nic.in/mp.htm

Marchant, A. N., \& Davies, T. W. (1994). Refrigerated storage: real-time control using intelligent parameter passing. International Journal of Refrigeration, 17(2), 109-116. http://dx.doi.org/10.1016/0140-7007(94)90051-5

Marchant, A. N., Lidstone, P. H., \& Davies, T. W. (1994). Artificial Intelligence Techniques for the Control of Refrigerated Potato Stores Part 2: Heat and Mass Transfer Simulation. Journal of Agricultural Engineering Research, 58(1), 27-36. http://dx.doi.org/10.1006/jaer.1994.1032

Nourian, F., Ramaswamy, H. S., \& K. A. C. (2003). Kinetics of quality change associated with potatoes stored at different temperatures. LWT - Food Science and Technology, 36(1), 49-65. http://dx.doi.org/10.1016/S0023-6438(02)00174-3

Oertel, K., \& Fischer, M. (1998). Adsorption cooling system for cold storage using methanol/silicagel. Applied Thermal Engineering, 18, 773-786. http://dx.doi.org/10.1016/S1359-4311(97)00107-5

Singh, R., Singh, S. P., \& Lazarus, I. J. (2014). Energy Performance Improvements in Indian Potato Cold Storages. Journal of Basic and Applied Scientific Research, 4(7), 44-50. Retrieved from http://www.textroad.com/ArticleView.aspx?articleId=JBASR-2874-2

Singh, R., Singh, S. P., \& S. R. N. (2010). Energy saving potential in Indian cold storages. In 2ndBharatiya Vigyan Sammelan. Indore.

Singh, S. P., Singh, R. K., \& Sodha, M. S. (2009). Empirical Relations for Orientation of Optimum Size Solar Efficient Cold Storage Building. SESI Journal, 19(1\&2), 32-39.

Sridar, N. (2013). The food wastage \& cold storage developing realistic solutions Infrastructure relationship in India. 
TERI. (2012). Retrieved from http://www.teriin.org/index.php?option=com_ongoing\&task=about_project\& pcode $=2009$ RT01

USAID. (2009). Private Sector Competitiveness Enhancement program. Cold chain and storage action plan.

Xie, J., Qu, X. H., Shi, J. Y., \& Sun, D. W. (2006). Effects of design parameters on flow and temperature fields of a cold store by CFD simulation. Journal of Food Engineering, 77(2), 355-363. http://dx.doi.org/10.1016/j.jfoodeng.2005.06.044

\section{Copyrights}

Copyright for this article is retained by the author(s), with first publication rights granted to the journal.

This is an open-access article distributed under the terms and conditions of the Creative Commons Attribution license (http://creativecommons.org/licenses/by/3.0/). 